\title{
THE S-COMMERCE USAGE AND ACCEPTANCE MODELLING IN MALAYSIA
}

Samer Bamansoor

Ph.D. Candidate, Faculty of Informatics and Computing, UniSZA, (Malaysia). E-mail: Si2398@putra.unisza.edu.my ORCID: https://orcid.org/0000-0001-8982-6674

Syarilla Iryani A. Saany

Associate Professor Dr., Faculty of Informatics and Computing, UniSZA, (Malaysia). E-mail: syarilla@unisza.edu.my ORCID: https://orcid.org/0000-0003-0764-2754

Yousef A. Baker El-Ebiary

Associate Professor Ts. Dr., Faculty of Informatics and Computing, UniSZA University, (Malaysia). E-mail: yousefelebiary@unisza.edu.my ORCID: https://orcid.org/0000-0002-4392-8015

Recepción: 06/01/2020 Aceptación: 27/02/2020 Publicación: 30/03/2020

\section{Citación sugerida:}

Bamansoor, S., Saany, S. I. A., y El-Ebiary, Y. A. B. (2020). The S-Commerce usage and acceptance modelling in Malaysia. 3C TIC. Cuadernos de desarrollo aplicados a las TIC, 9(1), 99-115. http://doi.org/10.17993/3ctic.2020.91.99-115 


\section{ABSTRACT}

The evolution of technology acceptance theories and models have started since the beginning of the 20th century and it is still evolving. This evolution is happened in different theoretical perspectives, such as: cognitive, affective, motivational, and behavioral intentions and reactions for individuals. Nowadays, understanding the reason of accepting or rejecting any new technology by users has become one of the most important areas in the IT field. The social media applications are benefited and enhanced the E-Commerce, Electronic Marketing (E-Marketing), and Electronic Shopping (E-Shopping) usage behaviors to get any information of any offered commodity in the easiest, fastest, and most familiar way, that will increase the retail profit as well. Social Commerce (S-Commerce) has become one of the most important fields and one of the fastest growing areas of the high technology sector development, especially in the trading and commercial environments. In this scope, it is presenting here the theories and models which were developed to study the acceptance by users and their adoption for new technology. this study adheres to the methodology of quantitative research, which offers a numerical measurement and analysis of the factors that determine adoption for samples 30 as a pilot study in Malaysia as a limit of this research specifically among 2 Malaysian Universities, that will lead to distribute the updated survey around 484 samples later. That results a high ratio of questionnaire validity and the effectiveness of the research hypothesis also found that the new model identifies the factors affecting S-Commerce usage behavior and continued usage intention, find the relationship between education and S-Commerce usage behavior and found such relationship between age and S- Commerce usage behavior.

\section{KEYWORDS}

E-Commerce, S-Commerce, Information systems, Electronic Enterprise. 


\section{INTRODUCTION}

At the time being, it is clearly perceived the rapid changes and developments in technology. So, many people name this generation as the speed generation. In these days, nobody denies the high prevalence of the use of smart devices. For example, smart phones have become an integral part of the lives of many people with all its creative facilities. The increasing number of people who own smart devices leads to increasing in the growth of social networks over the world. The variation in people interests and their ways to use the technology explains the current massive diversity of services, applications, and social networks as well.

In this context, Electronic Commerce (E-Commerce) has become one of the most important fields and one of the fastest growing areas of the high technology sector development, especially in the trading and commercial environments (Mahajan \& Agarwal, 2015). It is the newest way for companies and individuals to make profit and meet their requirements. These requirements are met by E-Commerce. Due to advancement of technologies in Malaysia, organizations have utilized the internet to manage the information and conform E-Commerce into their business processes.

Herein, the social media tools are benefited and enhanced the E-Commerce, Electronic Marketing (E-Marketing), and Electronic Shopping (E-Shopping) usage behaviors to get any information of any offered commodity in the easiest, fastest, and most familiar way, that will increase the retail profit as well (Foltz, Newkirk, \& Schwager, 2016). Apart from that, Social Commerce (S-Commerce) is: "a term that often used to describe new online retail models, or marketing strategies that incorporate established social networks and/or peer-to-peer communication to drive sales". Also S-Commerce as: "a technologyenabled shopping experience where online consumer interactions while shopping provide the main mechanism for conducting social shopping activities" (Yeng et al., 2015). 


\section{BACKGROUND AND LITERATURE REVIEW}

Social commerce, which is known as social business, is considered as a subset of electronic commerce. It refers to electronic commerce transaction that are delivered thru social media. In another word, social commerce made from integration of electronic commerce, electronic marketing using Web 2.0, social media and supporting technologies. Social commerce is the evolution of the social Web and social media. Customer service areas, online sales transactions, marketing communications, and user-generated content networks are determined as the major useful activities of social commerce. Furthermore, activities relevant to recruiting, collaborations, and problem solving are other important activities of social commerce. Another benefit of social commerce is to make the organizations closer to their markets for collaboration by using social networks. This kind of collaborations give rise to product innovation as well as greater customer value (Sharma \& Crossler, 2014).

Social commerce has significant monetary and strategic benefits for industries and organizations. Social commerce has benefits for three parties including customers, enterprises, and retailors. Customer can get recommendation easily for a particular product using product reviews, group discussion, etc. In addition, their purchase can be matched with specific needs which increases satisfaction and reduce selection decision time. Social commerce is easy for customer to use and it fits the mobile device lifestyle. It encourages customers to help other customers and finally their trust will be increased. One of the benefit of social commerce for retailors is providing feedback by customers on market communication strategies and the product itself. The website traffic will be increased by using social commerce and therefore the sales and revenue will be more. In addition, the vendors can get free word-of-mouth marketing. Enterprises can conduct faster requirement using social commerce and foster their relationship with partners locally and internationally (Turban, Strauss, \& Lai, 2016).

Briefly put, this study investigates Unified Theory Acceptances and Use Technology UTAUT and UTAUT2 theory within an unstable environment by looking at the joint impact of multiple variables in explaining Social Commerce usage behavior. To look at it in further detail, the effects of many 
variables, such as Performance Expectancy (PE), Social Influence (SI), Facilitating Conditions (FC), Effort Expectancy (EE), Hedonic Motivation (HM), Habit (H), Education (EDU), Age (AGE), Social commerce Usage Behavioural (UB) and continued usage intention of (CUI) were examined in an unstable environment to test UTAUT's general applicability. Also, two external factors namely Trust factor (TF), and cultures $(\mathbf{C})$ were also measured (Nur Adlia, 2015).

This review shows the UTAUT and UTAUT2 model as a powerful and flexible to enable studying the adoption of any new technology. This research work is identified as being of importance to researchers in technology acceptance field in providing them with the necessary background for their studies. And as a result, this review points out to the road which leads to this research for the purpose of extending the model depending on its tested technology and the proposed research sample. The following Figure 1 depicts the illustration of UTAUT.

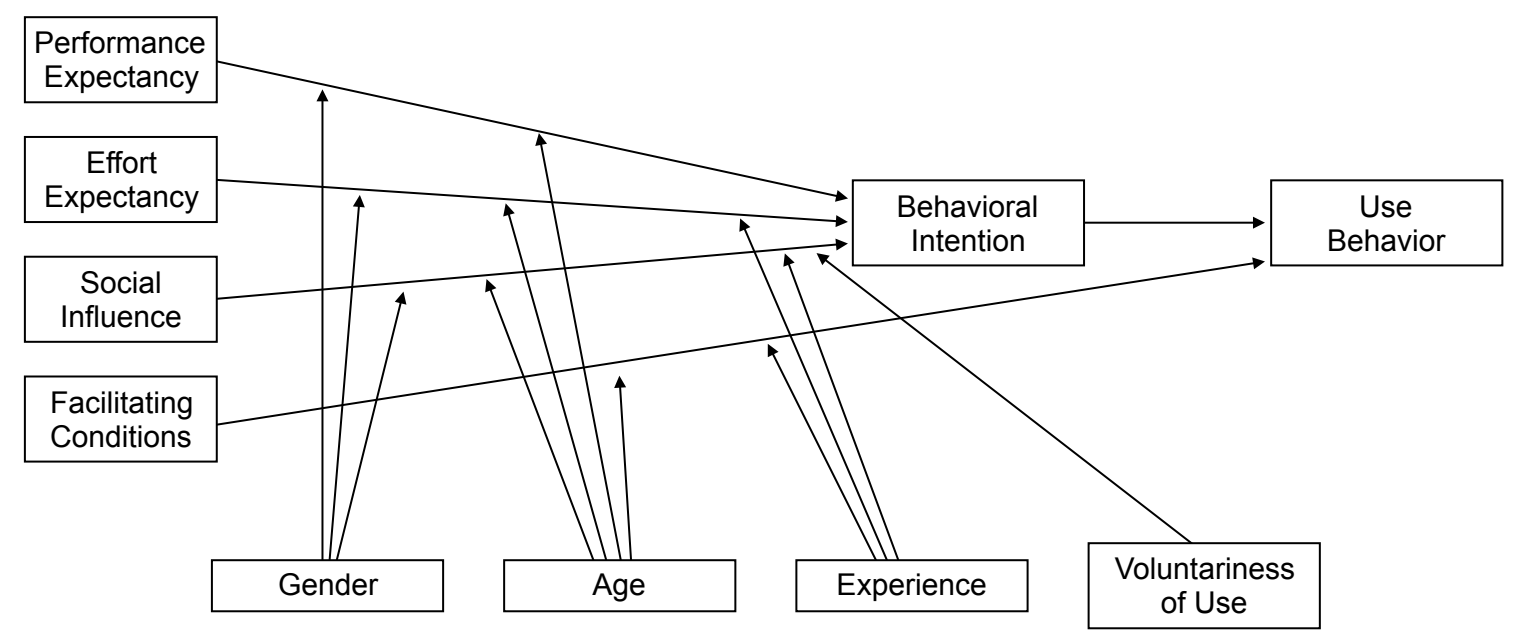

Figure 1. Unified Theory of Acceptance and Use of Technology.

As the focus of this study is on S-Commerce usage behavior, UTAUT is used to form a research framework; however, UTAUT did not include costumer-related construct. Therefore, as customer-related constructs 
are important for S-Commerce, UTAUT2 is considered in this study. UTAUT2 is an adapted model, which added three customer-related constructs into UTAUT, including (1) Hedonic Motivation (HM), (2) Price Value (PV), and (3) Habit as shown in Figure 2. Hedonic Motivation (HM) refers to the fun and pleasure that consumer experienced from use of technology whereas Price Value (PV) is related to the monetary cost of using technology. Finally, Habit is related to the behavior that consumers behave automatically for using technology (Nur Adlia, 2015).

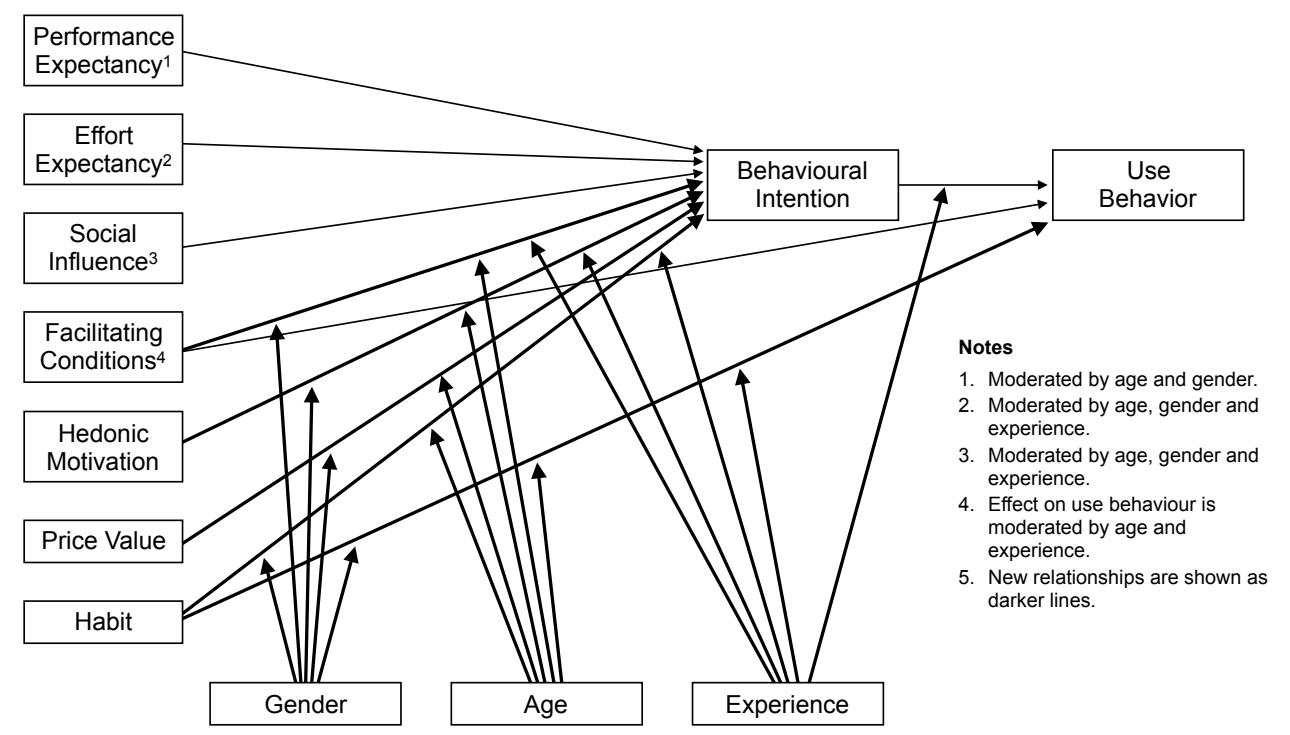

Figure 2. UTAUT2.

\section{PROBLEM STATEMENT}

Despite all the promised benefits of using Social Commerce services and their utilizations in Malaysia, the citizens are still reluctant in using new methods of business such as S- Commerce as a subset of E-Commerce services. Malaysians are still in conservative mindset that make the reluctant to change in adapting new technologies in their business processes (Othman et al., 2019). The basic curiosity is about why the customers and the public are reluctant to use S- Commerce to secure Social media through 
Social websites and about the linkage between such reluctance and the percentage of Malaysian society adopting the Social Commerce (Lim, Lim, \& Trakulmaykee, 2018).

From the practical perspective, the present study proves its significance by presenting an understanding of one of the most important concerns among Malaysian citizens, which is the acceptance of S-Commerce services. Hence, the factors with the capacity to impact the citizen's usage of S-Commerce services in Malaysia are determined. Consequently, the factors will reduce the citizen's resistance in utilizing S- Commerce services. Knowledge gap and emphasized the importance of the clear utilization of SCommerce services for the potential users i.e. the citizens. This gap is the motivation behind this study which focuses on using a new model for the purpose of tweaking the usage of S- Commerce services among the citizens in Malaysia by giving encouragement to them in employing the S-Commerce services at anytime and anywhere (Hashim, Nor, \& Janor, 2017).

Based on the above, there is a need to come up with a new model that increases the usage of S- Commerce services within developing countries, particularly in the context of Malaysia. This proposed model will facilitate the understanding of how factors tend to give effect on the level of S-Commerce services usage in Malaysia. In turn, this model will greatly contribute in boosting the level of usage of S- Commerce services in developing countries, in particular, Malaysia (El-Ebiary et al., 2018).

\section{RESEARCH METHODS}

For the achievement of the objectives of the research, this study adheres to the methodology of quantitative research, which offers a numerical measurement and analysis of the factors that determine adoption. Further, this study according to pilot study concept for 30 samples. but survey questionnaires will be distributed to 484 respondents, and these will be used in the results aggregation. The investigation has the aim to identify whether or not the independent variables and control variables significantly impacted the utilization of S- Commerce services. 


\section{PROPOSED MODEL AND HYPOTHESIS DEVELOPMENT}

This study has the intention to examine the aspect of acceptance of S-Commerce services by looking into the citizen's intention to use besides the Continued Usage Intention of S-Commerce services. This notion is selected because this study seeks to scrutinize the acceptance as well as its level, and to achieve this, both data of Continued Usage Intention and Use Behavior will be assessed. Another reason for using these data is that, the data of Continued Usage Intention gives good indication of use continuation in the future, and this is crucial when concerning S-Commerce. Online service utilization implies continuance in service adoption and for this reason, this study uses the construct of intention to use in addition to that of behaviour usage for gauging citizens' acceptance of S-Commerce.

The model used in this study extends the UTAUT2 concept of belief through the inclusion of eight more constructs namely, Performance Expectancy (PE), Social Influence (SI), Facilitating Conditions (FG), Effort Expectancy (EE), Hedonic Motivation (HM), Habit (H), Trust Factor (TF), Culture (C), Use Behavior (UB) and Continued Usage Intention (CUI) and Moderator Variables (MV) namely Education "E" and Age "A". As we shall see below, this study develops the following hypotheses:

H1: Performance Expectancy positively affect use behaviour of social commerce.

H2: Social Influence positively affect use behaviour of social commerce.

H3: Facilitating Condition positively affect use behaviour of social commerce.

H4: Effort Expectancy positively affect use behaviour of social commerce.

H5: Trust Factor positively affect use behaviour of social commerce.

H6: Culture positively affect use behaviour of social commerce.

H7: Hedonic Motivation positively affect use behaviour of social commerce.

H8: Habit positively affect use behaviour of social commerce. 
H9: Use Behaviour positively affect Continued Usage Intention of social commerce.

All hypotheses are intertwined, and they are the building blocks of the model recommended in this current work. The model suggested by the study is the S-Commerce Acceptance Model.

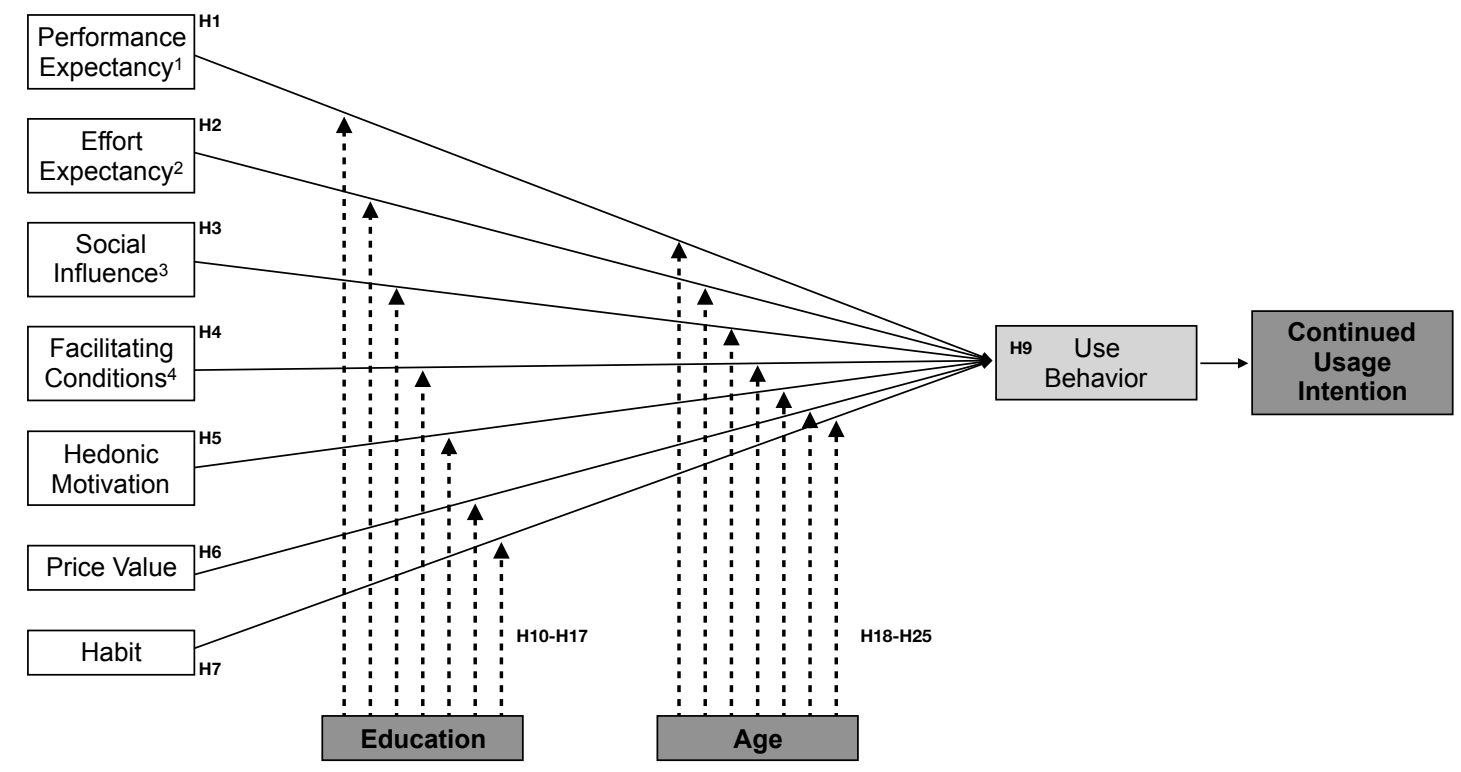

Figure 3. The Proposed Conceptual model.

Education plays a role of moderator between independent variables and use behaviour in this study. Therefore, eight hypotheses are proposed as followings based on the proposed model illustrated in Figure 3.

H10: Education moderates the positive relationship between Performance Expectancy and Use Behaviour.

H11: Education moderates the positive relationship between Social Influence and Use Behaviour.

H12: Education moderates the positive relationship between Facilitating Condition and Use Behaviour. 
H13: Education moderates the positive relationship between Effort Expectancy and Use Behaviour.

H14: Education moderates the positive relationship between Trust and Use Behaviour.

H15: Education moderates the positive relationship between Culture and Use Behaviour.

H16: Education moderates the positive relationship between Hedonic Motivation and Use Behaviour.

H17: Education moderates the positive relationship between Habit and Use Behaviour.

Age is also considered as another moderator between independent variables and use behaviour in this study. Another framework is proposed to show this moderating effect which is illustrated in Figure 3. Eight hypotheses are also proposed to test age as the moderator in this framework.

H18: Age moderates the positive relationship between Performance Expectancy and Use Behaviour.

H19: Age moderates the positive relationship between Social Influence and Use Behaviour.

H20: Age moderates the positive relationship between Facilitating Condition and Use Behaviour.

H21: Age moderates the positive relationship between Effort Expectancy and Use Behaviour.

H22: Age moderates the positive relationship between Trust and Use Behaviour.

H23: Age moderates the positive relationship between Culture and Use Behaviour.

H24: Age moderates the positive relationship between Hedonic Motivation and Use Behaviour.

H25: Age moderates the positive relationship between Habit and Use Behaviour.

\section{RESULT AND DISCUSSION}

Twenty-five (25) hypotheses about S-Commerce services within the situation of citizens residing in Malaysia have been formulated by various scholars, and since specific research methodology shall be required in testing these formulated hypotheses, this part will shed light on 25 relevant research designs 
and methodologies. This will encompass the descriptions of the research design, population, sampling methods and sample size, research instrument, pilot test, final instrument, data collection procedure as well as the technique of data analysis.

Convergent validity is the degree to which the perceived variables of certain construct demonstrates a high percentage of the variance in common. As added by the authors, the constructs' convergent validity is assessed using factor loadings, Average Variance Extracted (AVE), as well as Construct Reliability (CR) estimation. In particular, the authors proposed the value of 0.7 or greater as the best estimate of standardized loading whereas for the estimation of AVE, the obtained value should be more than 0.5. With respect to reliability estimate, the obtained value should be more than 0.7 . If all the proposed values are met, convergent validity is met. Accordingly, to measure the convergent validity, the least possible cut-off criteria employed in this study are: loadings $>0.7$, AVE $>0.5$, and reliability $>0.7$.

Discriminant validity is viewed as the degree to which a latent construct is totally different when compared with other latent constructs. The assessment of discriminant validity a method which entails the comparison of the extracted average variance of each construct with the respective Squared Inter Construct Correlations (SIC). Furthermore, the AVE estimate that is constantly bigger than those of SIC denotes support for the construct's discriminant validity. The current study employs this procedure in the discriminant validity assessment for all constructs.

Table 1. Validity pilot Test (Factors Analysis Loadings for Model).

\begin{tabular}{|c|c|c|c|c|c|c|c|c|c|c|}
\hline \multirow[b]{2}{*}{$\begin{array}{c}\text { Cod } \\
\#\end{array}$} & \multicolumn{10}{|c|}{ Variables } \\
\hline & $\begin{array}{c}\text { Performance } \\
\text { expectancy }\end{array}$ & $\begin{array}{c}\text { Social } \\
\text { influence }\end{array}$ & $\begin{array}{l}\text { Facilitating } \\
\text { conditions }\end{array}$ & $\begin{array}{c}\text { Effort } \\
\text { expectancy }\end{array}$ & $\begin{array}{l}\text { Trust } \\
\text { factor }\end{array}$ & Culture & $\begin{array}{l}\text { Hedonic } \\
\text { motivation }\end{array}$ & Habit & $\begin{array}{c}\text { Use } \\
\text { behaviour }\end{array}$ & $\begin{array}{c}\text { Continued } \\
\text { usage } \\
\text { intention }\end{array}$ \\
\hline PE1 & .644 & & & & & & & & & \\
\hline PE2 & .574 & & & & & & & & & \\
\hline PE3 & .954 & & & & & & & & & \\
\hline PE4 & .928 & & & & & & & & & \\
\hline PE5 & .901 & & & & & & & & & \\
\hline SI1 & & .941 & & & & & & & & \\
\hline
\end{tabular}




\begin{tabular}{|c|c|c|c|c|c|c|c|c|c|c|}
\hline \multirow[b]{2}{*}{$\begin{array}{c}\text { Cod } \\
\#\end{array}$} & \multicolumn{10}{|c|}{ Variables } \\
\hline & $\begin{array}{l}\text { Performance } \\
\text { expectancy }\end{array}$ & $\begin{array}{c}\text { Social } \\
\text { influence }\end{array}$ & $\begin{array}{l}\text { Facilitating } \\
\text { conditions }\end{array}$ & $\begin{array}{c}\begin{array}{c}\text { Effort } \\
\text { expectancy }\end{array}\end{array}$ & $\begin{array}{l}\text { Trust } \\
\text { factor }\end{array}$ & Culture & $\begin{array}{c}\text { Hedonic } \\
\text { motivation }\end{array}$ & Habit & $\begin{array}{c}\text { Use } \\
\text { behaviour }\end{array}$ & $\begin{array}{c}\text { Continued } \\
\text { usage } \\
\text { intention }\end{array}$ \\
\hline $\mathrm{SI} 2$ & & .896 & & & & & & & & \\
\hline $\mathrm{SI} 3$ & & .894 & & & & & & & & \\
\hline $\mathrm{S} 14$ & & .675 & & & & & & & & \\
\hline SI5 & & .710 & & & & & & & & \\
\hline FC1 & & & .529 & & & & & & & \\
\hline $\mathrm{FC} 2$ & & & .876 & & & & & & & \\
\hline FC3 & & & .862 & & & & & & & \\
\hline FC4 & & & .840 & & & & & & & \\
\hline FC5 & & & .606 & & & & & & & \\
\hline EE1 & & & & .949 & & & & & & \\
\hline EE2 & & & & .945 & & & & & & \\
\hline EE3 & & & & .874 & & & & & & \\
\hline EE4 & & & & .948 & & & & & & \\
\hline EE5 & & & & .895 & & & & & & \\
\hline $\mathrm{T} 1$ & & & & & .937 & & & & & \\
\hline T2 & & & & & .879 & & & & & \\
\hline T3 & & & & & .883 & & & & & \\
\hline T4 & & & & & .724 & & & & & \\
\hline C1 & & & & & & .787 & & & & \\
\hline $\mathrm{C} 2$ & & & & & & .949 & & & & \\
\hline C3 & & & & & & .871 & & & & \\
\hline $\mathrm{C} 4$ & & & & & & .969 & & & & \\
\hline HM1 & & & & & & & .949 & & & \\
\hline HM2 & & & & & & & .724 & & & \\
\hline HM3 & & & & & & & .928 & & & \\
\hline HM4 & & & & & & & .896 & & & \\
\hline $\mathrm{H} 1$ & & & & & & & & .675 & & \\
\hline $\mathrm{H} 2$ & & & & & & & & .949 & & \\
\hline $\mathrm{H} 3$ & & & & & & & & .879 & & \\
\hline $\mathrm{H} 4$ & & & & & & & & .883 & & \\
\hline
\end{tabular}




\begin{tabular}{|c|c|c|c|c|c|c|c|c|c|c|}
\hline \multirow[b]{2}{*}{$\begin{array}{c}\text { Cod } \\
\#\end{array}$} & \multicolumn{10}{|c|}{ Variables } \\
\hline & $\begin{array}{l}\text { Performance } \\
\text { expectancy }\end{array}$ & $\begin{array}{c}\text { Social } \\
\text { influence }\end{array}$ & $\begin{array}{l}\text { Facilitating } \\
\text { conditions }\end{array}$ & $\begin{array}{c}\text { Effort } \\
\text { expectancy }\end{array}$ & $\begin{array}{l}\text { Trust } \\
\text { factor }\end{array}$ & Culture & $\begin{array}{l}\text { Hedonic } \\
\text { motivation }\end{array}$ & Habit & $\begin{array}{c}\text { Use } \\
\text { behaviour }\end{array}$ & $\begin{array}{c}\text { Continued } \\
\text { usage } \\
\text { intention }\end{array}$ \\
\hline UB1 & & & & & & & & & .846 & \\
\hline UB2 & & & & & & & & & .985 & \\
\hline UB3 & & & & & & & & & .971 & \\
\hline UB4 & & & & & & & & & .967 & \\
\hline CUI1 & & & & & & & & & & .979 \\
\hline CUI2 & & & & & & & & & & .981 \\
\hline CUI3 & & & & & & & & & & .978 \\
\hline CUI4 & & & & & & & & & & .670 \\
\hline
\end{tabular}

Pilot test enables the researcher to determine the reliability of the measurement instruments before the main empirical work is carried out. Accordingly, the notion of reliability has been described as the degree to which a test unfailingly measures what is being measured. Additionally, Cronbach's alpha is employed in the measurement of the initial reliability of internal consistency concerning the data generated by the pilot study carried out prior to the actual study. With respect to the value of Cronbach alpha, it is increasable within either the average correlation or the number of items.

The context of survey test, as to allow its inclusion, the value obtained for the "item-to-total-test" correlation should fall in the range of $0.3-0.7$. This will be followed by a comprehensive analysis of reliability executed the complete dataset. For reliability coefficient with a high value, it denotes highly reliable instrument. Consequently, mentioned that for a start, the minimum satisfactory reliability coefficients should fall in the range of 0.70-0.80. In particular, the value must be higher than 0.7. For pilot test, concerning the sample size, it should be at least 30 . Following this recommendation, a total of 30 randomly chosen citizens were solicited to partake in this study's pilot test. The citizens were all from Al- Madinah International University and University Utara Malaysia in Kuala Lumpur. Accordingly, Table 2 shows the results generated from the test. The prerequisites discussed in this paragraph guide this study in its execution of reliability and factor analysis test. 
Table 2. Scale Reliability Alpha - Pilot Test of Model's Questionnaire (N=30).

\begin{tabular}{|c|c|c|}
\hline Variable & N. of Items & Alpha (a) \\
\hline Performance Expectancy & 5 & .802 \\
\hline Social Influence & 5 & .808 \\
\hline Facilitating Conditions & 5 & .890 \\
\hline Effort Expectancy & 5 & .815 \\
\hline Trust Factor & 4 & .702 \\
\hline Culture & 4 & .877 \\
\hline Hedonic Motivation & 4 & .743 \\
\hline Habit & 4 & .704 \\
\hline Use Behavior & 4 & .724 \\
\hline Continued Usage Intention & 4 & .707 \\
\hline
\end{tabular}

\section{CONCLUSION}

The research design and methodology are the highlighted and present the research model that applies the quantitative method using an organized questionnaire. The methodical (and random) sampling process is used for this study with a sample comprised 484 respondents whom were citizens from four regions of west Malaysia. Then, the subject of pilot study as a procedure to refine the research instrument, based on the reliability analysis results, and on the content validity of the construct. Finally, the description of the data collection procedure and the data analysis techniques which will be applied in this study.

\section{ACKNOWLEDGEMENT}

This research was supported by foundation from Universiti Sultan Zainal Abidin (UniSZA), therefore we thank our Universiti Sultan Zainal Abidin (UniSZA) that provided insight and expertise that greatly assisted the research.

Main Author: Samer Bamansoor.

Corresponding Author: Yousef A. Baker El-Ebiary.

Co-Authors: Syarilla Iryani A. Saany. 


\section{REFERENCES}

El-Ebiary, Y. A. B., Abu-Ulbeh, W., Alaesa, L., \& Hilles, S. (2018). Mobile Commerce in MalaysiaOpportunities and Challenges. Advanced Science Letters, 24(6), 4126-4128. https://doi.org/10.1166/ asl.2018.11555

Hashim, N. A., Nor, S. M., \& Janor, H. (2017). Riding the waves of social commerce: An empirical study of Malaysian entrepreneurs. Geografia-Malaysian fournal of Society and Space, 12(2). https:// www.researchgate.net/publication/298789173_Riding_the_waves_of_social_commerce_An_ empirical_study_of_Malaysian_entrepreneurs

Lim, S. G., Lim, S. P., \& Trakulmaykee, N. (2018). An empirical study on factors affecting e-commerce adoption among SMEs in west Malaysia. Management Science Letters, 8, 381-392. http://www. growingscience.com/msl/Vol8/msl_2018_21.pdf

Mahajan, P., \& Agarwal, M. (2015). Exploring the Potential of E-Commerce in the Digital Age: Challenges and Opportunities for Commerce Education. IUP Journal of Information Technology, 11(4). http:/ / connection.ebscohost.com/c/articles / 112375382 / exploring-potential-e-commercedigital-age-challenges-opportunities-commerce-education

Nur Adlia, M. (2015). Understanding the determinants of s-commerce adoption: From unified theory of acceptance and use of technology (UTAUT) perspective (Doctoral dissertation, Universiti Utara Malaysia). http:// etd.uum.edu.my/5286/

Othman, A. K., Hassan, L. F. A., Hamzah, M. I., Razali, A. R., Saim, M. A. S., Ramli, M. S., \& Azhar, M. A. A. (2019). The Influence of Social Commerce Factors on Customer Intention to Purchase. Asian Themes in Social Sciences Research, 3(1), 1-10. https: / /www.researchgate. net/publication/335915937_The_Influence_of_Social_Commerce_Factors_on_Customer_ Intention_to_Purchase 
Sharma, S., \& Crossler, R. E. (2014). Intention to engage in social commerce: uses and gratifications approach. AMCIS. https://www.semanticscholar.org/paper/Intention-to-Engage-in-SocialCommerce\%3A-Uses-and-Sharma-Crossler/ac5bc6c62087517103181c040ac7b283e45a7954

Turban, E., Strauss, J., \& Lai, L. (2016). Social commerce: Marketing, technology and management (1st ed.). Springer.

Yeng, S. K., Osman, A., Haji-Othman, Y., \& Safizal, M. (2015). E-commerce adoption among small and medium enterprises (SMEs) in Northern State of Malaysia. Mediterranean Fournal of Social Sciences, 6(5), 37. https://www.researchgate.net/publication/282889493_E-Commerce_ Adoption_among_Small_and_Medium_Enterprises_SMEs_in_Northern_State_of_Malaysia 
